\title{
The academic view up front: towards a new macroeconomics
}

\section{Paul De Grauwe}

\section{INTRODUCTION}

One of the surprising developments in macroeconomics is the systematic incorporation of the paradigm of the utility maximizing forward-looking and fully informed agent into macroeconomic models. The most successful implementations of these developments are to be found in the Dynamic Stochastic General Equilibrium (DSGE) models that are increasingly used in central banks for policy analysis (see Smets and Wouters, 2003, 2007).

These developments are surprising. While macroeconomic theory enthusiastically embraced the view that agents fully understand the structure of the underlying models in which they operate, other sciences like psychology and neurology increasingly uncovered the cognitive limitations of individuals (see for example Kahneman, 2002; Camerer et al., 2005; Kahneman and Thaler, 2006; Della Vigna, 2007). We learn from these sciences that agents only understand small bits and pieces of the world in which they live, and instead of maximizing continuously taking all available information into account, agents use simple rules (heuristics) in guiding their behaviour and their forecasts about the future. The recent financial crisis seems to support the view that agents have limited understanding of the big picture. If they had understood the full complexity of the financial system they would have understood the lethal riskiness of the assets they massively took in their portfolios.

In order to understand the nature of different macroeconomic models it is useful to make a distinction between top-down and bottom-up systems. In its most general definition a top-down system is one in which agents fully understand the system. These agents are capable of representing the whole system in a blueprint that they can store in their mind. Depending on their position in the system they can use this blueprint to take over the command, or they can use it to optimize their own private welfare. These are systems in which there is a one-to-one mapping of the information embedded in the system and the information contained in the brain of one 
(or more) individuals. An example of such a top-down system is a building that can be represented by a blueprint and is fully understood by the architect.

Bottom-up systems are very different in nature. These are systems in which no individual understands the whole picture. Each individual understands only a very small part of the whole. These systems function as a result of the application of simple rules by the individuals populating the system. Most living systems follow this bottom-up logic. The market system is also a bottom-up system. The best description made of this bottom-up system is still the one made by Hayek (1945). Hayek argued that no individual exists who is capable of understanding the full complexity of a market system. Instead individuals only understand small bits of the total information. The main function of markets consists in aggregating this diverse information. If there were individuals capable of understanding the whole picture, we would not need markets. This was in fact Hayek's criticism of the 'socialist' economists who took the view that the central planner understood the whole picture, and would therefore be able to compute the whole set of optimal prices, making the market system superfluous. For further insightful analysis see Leijonhufvud (1993).

My contention is that the rational expectations models are the intellectual heirs of these central planning models. Not in the sense that individuals in these rational expectations models aim at planning the whole, but in the sense that, as the central planner, they understand the whole picture. These individuals use this superior information to obtain the 'optimum optimorum' for their own private welfare. In this sense they are top-down models.

In this chapter I will contrast the rational expectations top-down model with a bottom-up macroeconomic model. This will be a model in which agents have cognitive limitations and do not understand the whole picture (the underlying model). Instead they only understand small bits and pieces of the whole model and use simple rules to guide their behaviour. I will introduce rationality in the model through a selection mechanism in which agents evaluate the performance of the rule they are following and decide to switch or to stick to the rule depending on how well the rule performs relative to other rules. ${ }^{1}$

\section{A BEHAVIOURAL MACROECONOMIC MODEL}

In this section the broad outlines of the behavioural model are described (for more technical detail see De Grauwe (2009). The model consists of an aggregate demand equation, an aggregate supply equation and a Taylor rule. 
Aggregate demand is determined by the:

- real interest rate

- expected future output (the forward-looking term)

- lagged output (the backward-looking term) reflecting inertia in output.

Aggregate supply (New Keynesian Philips curve) determines inflation as a function of:

- expected future inflation (forward-looking term)

- lagged inflation (backward-looking term) expressing price and wage rigidities

- output gap.

The Taylor rule describes how the central bank sets the interest rate:

- to keep inflation close to target $\left(c_{1}\right)$

- to stabilize output $\left(c_{2}\right)$

- to smooth interest rates.

Agents are assumed to use simple rules (heuristics) to forecast the future output and inflation. The way I proceed is as follows. I start with a very simple forecasting heuristics and apply it to the forecasting rules of future output. I assume two types of forecasting rules. A first rule can be called a 'fundamentalist' one. Agents estimate the steady-state value of the output gap (which is normalized at 0 ) and use this to forecast the future output gap. A second forecasting rule is an 'extrapolative' one. This is a rule that does not presuppose that agents know the steady-state output gap. They are agnostic about it. Instead, they extrapolate the previous observed output gap into the future.

This kind of simple heuristic has often been used in the behavioural finance literature where agents are assumed to use fundamentalist and chartist rules (see Brock and Hommes, 1997; Branch and Evans, 2006; De Grauwe and Grimaldi, 2006). It is probably the simplest possible assumption one can make about how agents, which experience cognitive limitations, use rules that embody limited knowledge to guide their behaviour. In this sense they are bottom-up rules. They only require agents to use information they understand, and do not require them to understand the whole picture.

As indicated earlier, agents are rational in the sense that they continuously evaluate their forecast performance. I apply notions of discrete choice theory (see Anderson et al., 1992; Brock and Hommes, 1997) in specifying the procedure agents follow in this evaluation process. After an evaluation of the forecasting rule they use, agents decide to switch to the alternative forecasting rule if the latter performs better than the one being used. 
It should be stressed that although individuals use simple rules in forecasting the future, this does not mean that they fail to learn. In fact the fitness criterion used should be interpreted as a learning mechanism based on 'trial and error'. When observing that the rule they use performs less well than the alternative rule, agents are willing to switch to the more performing rule. Put differently, agents avoid making systematic mistakes by constantly being willing to learn from past mistakes and to change their behaviour. This also ensures that the market forecasts are unbiased.

A similar selection mechanism governs the use of forecasting rules of inflation. I assume two possible rules. The first one uses the announced inflation target to forecast the rate of inflation; the second one uses an extrapolative rule. This mechanism can be interpreted as a procedure of agents to find out how credible the central bank's inflation targeting is. If this is very credible, using the announced inflation target will produce good forecasts and as a result, the probability that agents will rely on the inflation target will be high. If on the other hand, the inflation target does not produce good forecasts (compared to a simple extrapolation rule) the probability that agents will use it will be small.

\section{ANIMAL SPIRITS}

I now present the simulations of the behavioural model in the time domain and I interpret them (for more information on how these simulations were designed, see De Grauwe, 2009). The upper panel of Figure X.1 shows the time pattern of output produced by the behavioural model. A strong cyclical movement in the output gap can be observed. The lower panel of Figure X.1 shows a variable called 'animal spirits'. ${ }^{2}$ It represents the evolution of the fractions of the agents who extrapolate a positive output gap. Thus when the curve reaches +1 all agents are extrapolating a positive output gap; when the curve reaches 0 no agents are extrapolating a positive output gap. In fact in that case they all extrapolate a negative output gap. Thus the curve shows the degree of optimism and pessimism of agents who make forecasts of the output gap.

Combining the information of the two panels in Figure X.1 it can be seen that the model generates endogenous waves of optimism and pessimism. During some periods optimists (that is, agents who extrapolate positive output gaps) dominate and this translates into above-average output growth. These optimistic periods are followed by pessimistic ones when pessimists (that is, agents who extrapolate negative output gaps) dominate and the growth rate of output is below average. These waves of optimism 

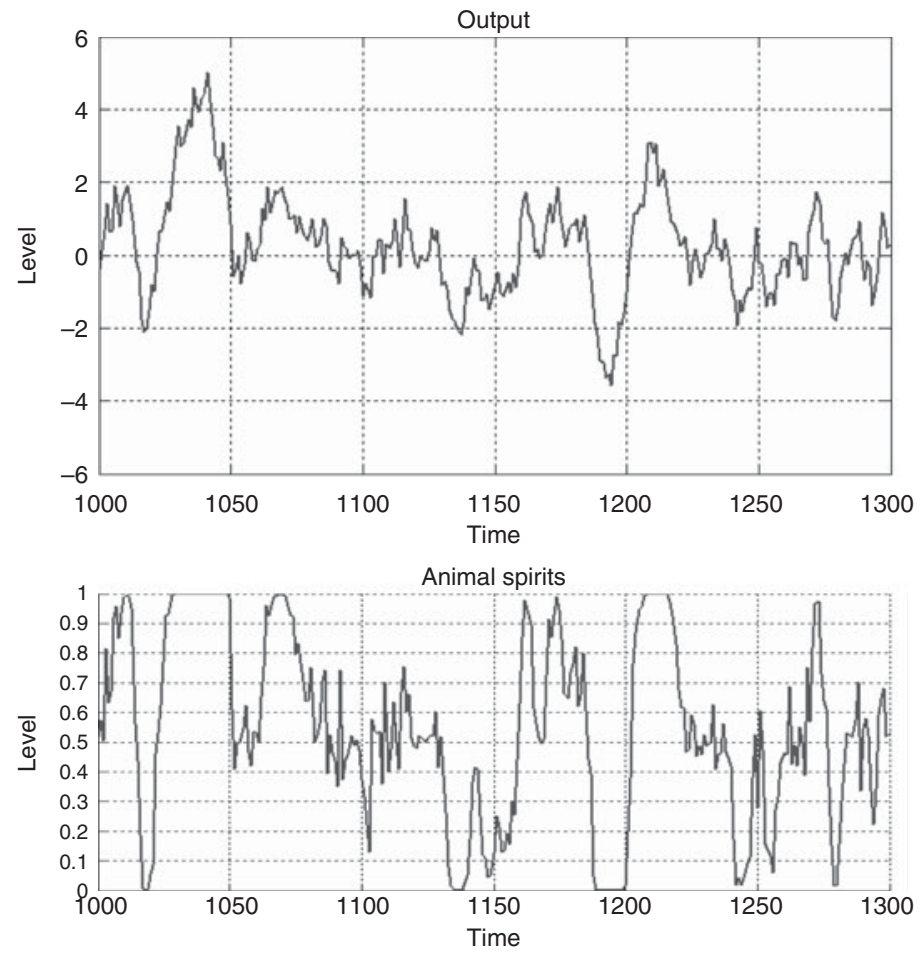

Figure X.1 Output gap in behavioural model

and pessimism are essentially unpredictable. Other realizations of the shocks produce different cycles with the same general characteristics.

These waves of optimism and pessimism can be understood to be searching (learning) mechanisms of agents who do not fully understand the underlying model but are continuously searching for the truth. An essential characteristic of this searching mechanism is that it leads to systematic correlation in beliefs (for example optimistic extrapolations or pessimistic extrapolations). This systematic correlation is at the core of the booms and busts created in the model. Note, however, that when computed over a significantly large period of time the average error in the forecasting goes to zero. In this sense, the forecast bias tends to disappear asymptotically.

Having presented the main features of the behavioural (bottom-up) model I now proceed to show how this model leads to a view of macroeconomic dynamics that contrasts greatly with the view obtained from the rational expectations (top-down) macroeconomic models. I concentrate on two areas. The first one has to do with the business cycle theories 
implicit in the behavioural and the rational expectations models. The second one focuses on the implications for monetary policies.

\section{TWO DIFFERENT BUSINESS CYCLE THEORIES}

The behavioural and rational expectations macroeconomic models lead to very different views on the nature of business cycle. Business cycle movements in the rational expectations (DSGE) models arise as a result of exogenous shocks (in productivity and preferences) and lags in the transmission of these shocks to output and inflation. Thus inertia in output and inflation are the result of the lagged transmission of exogenous shocks. One could call the inertia (and the business cycles) introduced in the DSGE model exogenously created phenomena. ${ }^{3}$

In contrast, the behavioural model presented here is capable of generating inertia (and business cycles) without imposing lags in the transmission process. This could be called endogenous inertia.

This difference between the two models is quite fundamental. In the rational expectations model and in the absence of lags in the transmission, agents immediately find the optimal levels of output and inflation after some unanticipated shock. This results from their top-down position, that is, they can instantaneously compute the effects this shock has on all the variables of the model making it possible to compute the optimal plan today and in the future. In order to produce the required inertia (and the business cycle movements), lags in the transmission preventing instantaneous adjustment to the optimal plan, are necessary.

The contrast with the behavioural model is great. Agents in this model do not fully understand how the shock will be transmitted. They have no topdown position. As a result they follow a procedure (heuristics together with a selection mechanism) that functions as a 'trial and error' learning mechanism aimed at revealing the information about shocks and the transmission process. This is a slow bottom-up process that uses backward evaluation processes. It generates an endogenous inertia (and business cycle) into the model.

The different natures of the business cycles in the DSGE models and the behavioural model also have policy implications. In the DSGE models now favoured by central banks, business cycle movements in output and prices originate from price and wage stickiness. In order to reduce this kind of volatility more flexibility in prices and wages is required. That is why many central banks call for more flexibility. In a more flexible world, central banks will not be called upon so often to stabilize output, and thereby set price stability at risk.

In the behavioural model, business cycle movements in output arise 
from informational inertia. Thus, even if prices and wages become more flexible, this will not necessarily reduce the business cycle movements in output. As a result, society's desire to stabilize output will not be reduced. And central banks that inevitably respond to these desires will face the need to stabilize output at the risk of reducing price stability.

\section{THE ROLE OF OUTPUT STABILIZATION}

Modern macroeconomics in general, and DSGE models in particular, have provided the intellectual foundation of inflation targeting. Until the eruption of the financial crisis in 2007, inflation targeting strategies had become the undisputed policy framework modern central banks should adopt. And most did. Inflation targeting, of course, does not imply that there is no role for output stabilization. DSGE modellers who have put a new Keynesian flavour in their models, have always stressed that wage and price rigidities provide a rationale for output stabilization by central banks (see Clarida et al., 1999; Galí, 2008). This idea has found its reflection in 'flexible' inflation targeting (Svensson, 1997; Woodford, 2003). Because of the existence of rigidities, a central bank should not attempt to keep inflation close to its target all the time. When sufficiently large shocks occur that lead to departures of inflation from its target, the central bank should follow a strategy of gradual return of inflation to its target.

Output stabilization in the DSGE world, however, is very much circumscribed. The need to stabilize arises because of the existence of rigidities in prices that makes it necessary to spread out price movements over longer periods. The limited scope for output stabilization is based on a model characterized by a stable equilibrium. There is no consideration of the possibility that the equilibrium may be unstable or that fluctuations in output have a different origin than price rigidities. Should the scope for output stabilization be enlarged? In order to shed some light on this issue we derive the trade-off between output and inflation variability in the context of the behavioural model, and we formulate some policy conclusions.

The trade-offs are constructed as follows. The model was simulated 10000 times and the average output and inflation variabilities were computed for different values of the Taylor rule parameters.

The trade-offs are shown in Figure X.2 for different values of the inflation parameter $c_{1}$. Take the trade-off A-B. This is the one obtained for $c_{1}=1$. Start from point A on the trade-off. In point A, the Taylor output parameter $c_{2}=0$ (strict inflation targeting). As output stabilization increases we first move downwards. Thus increased output stabilization by the central bank reduces output and inflation variability. The relation 


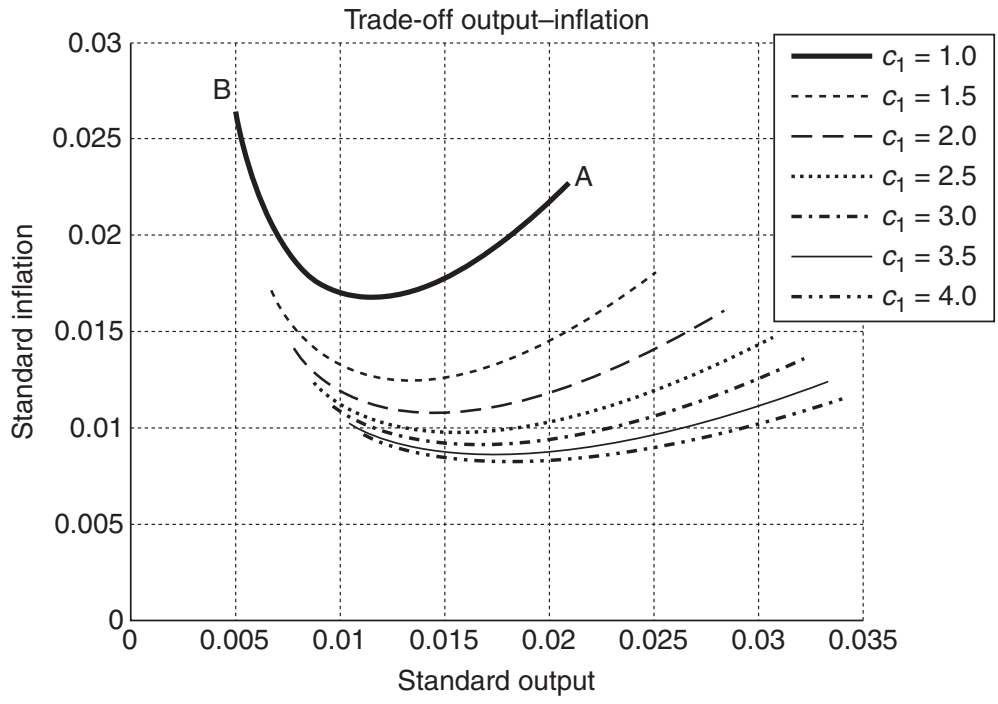

Figure X.2 Trade-offs in the behavioural model

is non-linear, however. At some point, with too high an output stabilization parameter, the trade-off curve starts increasing, becoming a 'normal' trade-off, that is, a lower output variability is obtained at the cost of increased inflation variability.

How can we interpret these results? Let us start from the case of strict inflation targeting, that is, the authorities set $c_{2}=0$. There is no attempt at stabilizing output at all. The ensuing output variability intensifies the waves of optimism and pessimism (animal spirits) which in turn feed back on output volatility. These larges waves lead to higher inflation variability. Thus, some output stabilization is good; it reduces both output and inflation variability by preventing too large swings in animal spirits. With no output stabilization at all $\left(c_{2}=0\right)$ the forces of animal spirits are so high that the high output variability also increases inflation volatility through the effect of the output gap on inflation (supply equation). Too much output stabilization, however, reduces the stabilization bonus provided by a credible inflation target. When the central bank attaches too much importance to output stabilization it creates more scope for better forecasting performance of the inflation extrapolators, leading to more inflation variability.

Figure X.2 also tells us something important about inflation targeting. We note that increasing the inflation parameter in the Taylor rule $\left(c_{1}\right)$ has the effect of shifting the trade-offs downwards, that is, the central bank can improve the trade-offs by reacting more strongly to changes in inflation. ${ }^{4}$ 
The central bank achieves this improvement in the trade-off because by reacting more intensely to changes in inflation it reduces the probability that inflation extrapolators will tend to dominate the market, and as a result it reduces the probability that inflation targeting looses credibility. Such a loss of credibility destabilizes both inflation and output. Thus maintaining credibility of inflation targeting is an important source of macroeconomic stability in our behavioural model.

One can conclude that the behavioural model provides a different perspective about the need to stabilize output. This is a model that creates endogenous movements of the business cycle that are correlated with waves of optimism and pessimism. They are also unrelated to the existence of wage and price rigidities. These waves of optimism and pessimism both influence the output gap and in turn are also influenced by the output gap.

\section{CONCLUSION}

Macroeconomic models based on rational expectations assume extraordinary cognitive capabilities of individual agents. The latter are assumed to be capable of understanding the whole picture. Recent developments in other disciplines including psychology and brain science document that individual agents struggle with limited cognitive abilities, restricting their capacity to understand the world. As a result, individual agents use small bits of information and simple rules to guide their behaviour.

I have used these new insights to show how a macroeconomic model in which the cognitive limitations of agents take centre stage functions. Once one moves into a world of cognitive limitations one faces the problem that agents use simple and biased rules to forecast output and inflation. In order to provide discipline in the use of these rules, a learning mechanism was introduced that allows for the selection of those rules that are more profitable than others.

The ensuing behavioural model produces a number of results that distinguishes it from the rational expectations models. First, the behavioural model creates correlations in beliefs which in turn generate waves of optimism and pessimism. The latter produce endogenous cycles which are akin to the Keynesian animal spirits.

A second result is that the inflation targeting regime turns out to be of great importance to stabilize the economy in a behavioural model. The reason is that credible inflation targeting also helps to reduce correlations in beliefs and the ensuing self-fulfilling waves of optimism and pessimism. However, and this is where the behavioural model departs from the rational expectations model, strict inflation targeting is not an optimal 
policy. Some output stabilization (given a credible inflation target) also helps in reducing the scope for waves of optimism and pessimism to emerge and to destabilize output and inflation.

Finally, the behavioural model provides for a very different theory of the business cycle as compared to the business cycle theory implicit in the rational expectations (DSGE) models. In the DSGE models, business cycle movements in output and prices arise because rational agents cannot adjust their optimal plans instantaneously after an exogenous disturbance. Price and wage stickiness prevent such instantaneous adjustment. As a result, these exogenous shocks produce inertia and business cycle movements.

In the behavioural model, business cycle movements in output arise from informational inertia. Thus, even if prices and wages become more flexible, this will not necessarily reduce the business cycle movements in output. As a result, society's desire to stabilize output will not be reduced. And central banks that inevitably respond to these desires will face the need to stabilize output.

\section{NOTES}

1. The modelling approach presented in this chapter is not the only possible one to model agents' behaviour under imperfect information. In fact, a large literature has emerged attempting to introduce imperfect information into macroeconomic models. These attempts have been based mainly on the statistical learning approach pioneered by Sargant (1993) and Evans and Honkapohja (2001). This literature leads to important new insights (see for example Orphanides and Williams (2004), Gaspar et al. (2006), Milani (2007)). See also the fascinating book of Gigerenzer and Todd (1999) on the use of simple heuristics as compared to statistical (regression) learning.

2. The locus classicus is Keynes (1936). See also Farmer (2006) and Akerlof and Shiller (2009).

3. In a way it can be said that the lags in the transmission mechanism introduce an exogenous, some may say an ad hoc, element into the logic of the DSGE model. To give an example, Calvo pricing in which firms are constrained to adjust prices instantaneously (Christiano et al., 2001) is routinely imposed in DSGE models. It is clear, however, that such a restriction comes from outside the logic of the model. In a world where everybody understands the model and each other's rationality, which is at the core of the DSGE models, agents would want to go immediately to the optimal plan using the optimal price. They would not want to accept such a restriction.

4. A similar result on the importance of strict inflation is also found in Gaspar et al. (2006) who use a macro model with statistical learning.

\section{REFERENCES}

Akerlof, G. and R. Shiller (2009), Animal Spirits. How Human Psychology Drives the Economy and Why It Matters for Global Capitalism, Princeton: Princeton University Press. 
Anderson, S., A. de Palma and J.-F. Thisse (1992), Discrete Choice Theory of Product Differentiation, Cambridge, MA: MIT Press.

Branch, W. and G. Evans (2006), 'Intrinsic heterogeneity in expectation formation', Journal of Economic Theory, 127, 264-95.

Brock, W. and C. Hommes (1997), 'A rational route to randomness', Econometrica, 65, 1059-95.

Camerer, C., G. Loewenstein and D. Prelec (2005), 'Neuroeconomics: how neuroscience can inform economics', Journal of Economic Literature, 63 (1), 9-64.

Christiano, L., M. Eichenbaum and C. Evans (2001), 'Nominal rigidities and the dynamic effects of a shock to monetary policy', NBER Working Paper, no. 8403, July.

Clarida, R., J. Galí and M. Gertler (1999), 'The science of monetary policy, a new Keynesian perspective', Journal of Economic Literature, 37, 1661-707.

De Grauwe, P. (2009), 'Bottom-up versus Top-down Macroeconomic Models', paper presented at the Annual Research Conference of DG-ECFIN of the European Commission, 15-16 October 2009, Brussels.

De Grauwe, P. and M. Grimaldi (2006), The Exchange Rate in a Behavioural Finance Framework, Oxford: Princeton University Press.

Della Vigna, S. (2007), 'Psychology and economics: evidence from the field', NBER Working Paper, no. 13420.

Evans, G.W. and S. Honkapohja (2001), Learning and Expectations in Macroeconomics, Princeton: Princeton University Press.

Farmer, Roger E.A. (2006), 'Animal Spirits', Palgrave Dictionary of Economics, London: Macmillan.

Galí, J. (2008), Monetary Policy, Inflation and the Business Cycle, Princeton: Princeton University Press.

Gaspar, V., F. Smets and D. Vestin (2006), 'Adaptive learning, persistence and optimal monetary policy’, ECB Working Paper Series No. 644, European Central Bank.

Gigerenzer, G. and P.M. Todd (1999), Simple Heuristics That Make Us Smart, New York: Oxford University Press.

Hayek, F. (1945), 'The use of knowledge in society', American Economic Review, XXXV (4), 519-30.

Kahneman, D. (2002), 'Maps of Bounded Rationality: A Perspective on Intuitive Judgment and Choice', Nobel Prize Lecture, 8 December, Stockholm.

Kahneman, D. and R. Thaler (2006), 'Utility maximization and experienced utility', Journal of Economic Perspectives, 20, 221-34.

Keynes, J.M. (1936), The General Theory of Employment, Interest and Money, London: Macmillan.

Leijonhufvud, A. (1993), 'Towards a not-too-rational macroeconomics', Southern Economic Journal, 1 (1), July.

Milani, F. (2007), 'Expectations, learning and macroeconomic persistence', Journal of Monetary Economics, 54, 2065-82.

Orphanides, A. and J. Williams (2004), 'Robust Monetary Policy with Imperfect Information', Discussion Paper, Board of Governors of the Federal Reserve System, Washington DC.

Sargant, T. (1993), Bounded Rationality in Macroeconomics, Oxford: Oxford University Press.

Smets, F. and R. Wouters (2003), 'An estimated dynamic stochastic general equilibrium model', Journal of the European Economic Association, 1, 1123-75. 
Smets, F. and R. Wouters (2007), 'Shocks and frictions in US business cycles - a Bayesian DSGE approach', ECB Working Paper Series No. 722, European Central Bank, February.

Svensson, L. (1997), 'Inflation forecast targeting: implementing and monitoring inflation targets', European Economic Review, 41, 111-46.

Woodford, M. (2003), Interest and Prices: Foundations of a Theory of Monetary Policy, Princeton: Princeton University Press. 